\title{
Vestidos para a sepultura: a escolha da mortalha fúnebre na Braga setecentista
}

\author{
Norberto Tiago Gonçalves Ferraz ${ }^{[1]}$
}

\begin{abstract}
Resumo
A vivência da morte na cidade de Braga durante o século XVIII implicava diferentes dimensões e práticas sociais e cultuais que pretendiam conferir aos defuntos uma viagem segura para o outro mundo. Uma dessas dimensões era a escolha da mortalha fúnebre. Neste artigo, fundado no estudo de uma amostra de 250 testamentos bracarenses setecentistas, procuramos assinalar as vestes fúnebres mais solicitadas pelos bracarenses dessa centúria e os motivos dessas escolhas. Salientamos igualmente o papel importante desempenhado por certas confrarias na aquisição da mortalha para seus membros.
\end{abstract}

Palavras-chave: mortalha; Braga; confraria.

\section{Dressed for the grave: the choice of the funeral shroud in the Braga of XVIII century}

\section{Abstract}

The experience of death in the city of Braga, during the XVIII century, implied diferent dimensions and social and cultual practices with the purpose of giving to the dead, a safe journey to the afterlife. One of those dimensions was the choice of the funeral shroud. In this article, based upon a sample of 250 testaments from people of Braga of the XVIII century, we try to mark the funeral shrouds more solicitated by the ihabitants of Braga in this century and the reasons for their choices. We also put in evidence the important role made by certain confraternities in the acquisition of the shroud to some of their members.

Keywords: shroud, Braga, confraternitie.

\section{Dressés pour la tombe : le choix du linceul pour les funerailles dans la Braga du XVIIIIe siècle}

\section{Résumé}

L'experience de la mort dans la cité de Braga pendant le XVIII ${ }^{\mathrm{e}}$ siècle avait implicite des dimensions et pratiques cultuels et sociales qui voulaient donner aux morts une voyage en securité pour l'autre monde. Une de ces dimensions était le choix du linceul. Dans cet article fondé dans létude d'un échantillon de 250 testaments des habitants de Braga au XVIII ${ }^{\mathrm{e}}$ siècle, nous voulons montrer les vêtements pour les funerailles plus demendés par les habitants de Braga dans ce siècle et les raisons de ses choix. Nous mettons également en évidence l'importance des confréries dans lachètement du linceul pour ses membres.

Mots-clés: linceul ; Braga ; confrérie.

\section{Vestidos para la sepultura: la eleccion de la mortaja para el funeral en la Braga setecentista}

\section{Resumen}

La vivencia de la muerte en la ciudad de Braga, en el siglo XVIII, tenia implícito diferentes dimensiones y prácticas sociales, asi como de culto religioso, destinadas a garantir a los muertos, un viagen seguro para el otro mundo. Una de las dimensiones era la eleccíon de la mortaja para el funeral. En este artigo, que se basa en un estúdio de 250 testamentos bracarenses setecentistas, procuramos mostrar las vestimentas fúnebres mas solicitadas por los bracarenses en esta centuria y los motivos de sus eleciones. También destacamos el importante papel hecho por ciertas hermandades en la compra de la mortaja para sus membros.

Palabras-clave: mortaja; Braga; hermandad. 
A

preparação do corpo do defunto para a última viagem englobava um aspecto importante, o qual era geralmente por ele determinado quando da elaboração do testamento. Por meio do estudo analítico de uma amostra de 250 testamentos bracarenses do século XVIII, ${ }^{2}$ tornou-se possível avaliar, ou pelo menos antever, o momento em que seus restos mortais eram envolvidos nas vestes que o amortalhavam. É certo que nem sempre as determinações dos testadores eram respeitadas na íntegra. Mas como esses casos eram a exceção, e na falta de outras fontes documentais, cremos que os dados obtidos em testamento refletem em grande medida a realidade. ${ }^{3}$ Ao longo dos séculos, as mortalhas utilizadas pelos defuntos, com as quais eram sepultados, conheceram uma evolução importante. Se, na Idade Média, pelo menos desde o século $\mathrm{X}$, os defuntos eram geralmente revestidos com um simples sudário ou lençol, a partir da Idade Moderna difundiu-se no mundo católico o costume de amortalhar os cadáveres com o hábito de uma ordem religiosa. ${ }^{4} \mathrm{O}$ uso dos hábitos referentes aos santos fundadores ou padroeiros de uma congregação religiosa, como mortalha, tinha uma função cristã escatológica. O objetivo era garantir a intercessão desse santo junto a Deus, como forma de assegurar a salvação eterna do indivíduo que envergasse essa veste envolvendo seus restos mortais. ${ }^{5}$

A análise dos dados compulsados demonstra uma preferência notória pela escolha do hábito de São Francisco de Assis. Cerca de $41 \%$ dos indivíduos de nosso estudo solicitaram esse hábito como a única veste de sepultamento. Todavia, se considerarmos também os testadores que incluíram a veste franciscana em conjunto com outra mortalha, constatamos que $56 \%$ deles escolheram o hábito de São Francisco de Assis para serem amortalhados. Esses resultados estão longe de ser surpreendentes, uma vez que se enquadram em uma tendência geral verificada em Portugal e na Europa católica da época moderna, patenteada por vários estudos que têm vindo a colocar em evidência sua preponderância entre as mortalhas. ${ }^{6}$ A razão para o impacto do hábito franciscano deveu-se à divulgação de uma crença, iniciada ainda na Idade Média e confirmada pelo Vaticano, que certificava a concessão de indulgências extraordinárias, garantias da salvação da alma, aos indivíduos que o envergassem após a morte. ${ }^{7}$ Ou seja, o hábito franciscano adquirira um cariz seguro de salvaguarda, relativamente à salvação da alma dos homens e mulheres da Idade Moderna, tornando-se um elemento incontornável nessa ocasião. Seu uso era

\footnotetext{
${ }^{2}$ Arquivo Distrital de Braga (ADB). Fundo dos testamentos de Provedoria; Arquivo da Igreja da Sé de Braga (AISB). Livro de testamentos da freguesia da Sé, 1738-1785, fls. 10-10v., 12-13, 19-19v., 26v.-27v., 32-33, 35-36, 40v.41, 50v-51, 67v-68, 74-75, 85-85v., 89-89v., 111v.-112, 129-130., 134v.-135, 135, 147-148, 160-161, 165v-166v., 175-176, 189, 197v.198; Livro de testamentos da freguesia da Sé, 1785-1814, fls. 5-5v., 37v.-38, 49v.-50, $57 \mathrm{v}$-58.

${ }^{3}$ Em Múrcia, a escolha da mortalha era um dos primeiros pontos de preocupação dos testadores. A esse respeito, ver Illán (1998, p. 100).

${ }^{4}$ A propósito da evolução da mortalha do sudário ou lençol para o hábito religioso, da Idade Média para a Moderna, ver Araújo (2000, p. 266).

${ }^{5}$ Sobre a função salvífica das mortalhas de santos, ver o que diz Rodrigues (1997, p. 196-198).

${ }^{6}$ Relativamente à difusão do uso da mortalha franciscana no mundo católico moderno, ver Gadow (1986, p. 100-101), García (2004, p. 445-446) e Rodeñas e Cruz (1988, p. 514).

${ }^{7}$ A propósito das indulgências concedidas aos portadores da mortalha franciscana, ver Fernández (1996, p. 160-162).
} 
também uma forma de manifestação de humildade e despojamento, pois São Francisco de Assis fora, em vida, um modelo de pobreza e de humildade cristãs. Desse modo, as garantias salvíficas concedidas pelo uso dessa mortalha, bem como a projeção de uma imagem pessoal de pobreza e humildade após a morte, quando, por vezes, essa imagem em nada tinha correspondido à vida do falecido, serviam como esperança e consolo para os defuntos, crentes na certeza da salvação.

\section{A partir da Idade Moderna difundiu-se no mundo católico o costume de amortalhar os cadáveres como hábito de uma ordem religiosa}

Todavia, é também notório que, a partir de meados da centúria, denota-se uma mudança por parte das mulheres bracarenses relativamente à escolha da mortalha. Os elementos do sexo feminino foram, progressivamente, colocando de parte o hábito franciscano em favor dos hábitos de Santa Teresa e de Nossa Senhora do Carmo, bem como os de Nossa Senhora da Conceição, também uma invocação popularizada pelos franciscanos. Levantamos a hipótese provável de o hábito de Santa Teresa do Carmo e o de Nossa Senhora do Carmo serem apenas uma única mortalha, de origem carmelita. No total, 15\% dos testadores analisados solicitaram somente o hábito carmelita, ou este em conjunto com uma segunda veste. Mas, se considerarmos apenas os testadores analisados referentes ao período posterior a 1760, essa percentagem aumenta substancialmente para $37 \%$. Os hábitos carmelitas referidos foram possivelmente popularizados pelos frades do convento de Nossa Senhora do Carmo de Braga, estabelecido no século XVII, bem como pelas freiras do convento de Santa Teresa de Jesus, fundado na prelatura do arcebispo d. Gaspar (17581789). Essa divulgação, notória sobretudo entre o sexo feminino, pode ter sido sustentada na base da concessão de importantes graças espirituais a quem usasse o hábito carmelita, à semelhança do sucedido com o hábito franciscano. ${ }^{8}$ De fato, já no século XIII São Simão Stock assegurara que a Virgem Maria lhe havia comunicado que a todos que usassem o escapulário carmelita ela intercederia no sentido de livrá-los das penas infernais, privilégios confirmados pelo papa João XXII. ${ }^{9}$ Na verdade, o crescimento da utilização do hábito de Santa Teresa foi igualmente assinalável em outras regiões do catolicismo

\footnotetext{
${ }^{8}$ Sobre as graças espirituais concedidas ao hábito carmelita, ver Marques (2000, p. 632). ${ }_{9}^{9}$ A esse propósito, ver Marques (2000, p. 631-632).
} 
europeu. ${ }^{10}$ Por seu turno, o hábito de Nossa Senhora da Conceição foi certamente difundido pelas religiosas do convento de mesmo nome, fundado em 1625 , localizado na cidade. ${ }^{11}$

Entre os solicitadores de apenas uma única mortalha, merecem também referência os que escolheram o hábito de São Bento e o das freiras dos Remédios, demonstrando a importância das ordens religiosas nesse aspecto da vivência da morte dos bracarenses. ${ }^{12}$ Outra mortalha mencionada esporadicamente foi o "hábito de viúva". Embora pouco saibamos sobre a especificidade dessa última veste, pensamos que seria elaborado como uma forma de distinguir o estado civil dessas mulheres, pois encontramos também menção ao amortalhamento de uma defunta com a veste de "moça solteira", por disposição posterior do irmão, seu herdeiro. ${ }^{13}$ Essa referência faz-nos supor que, pelo menos para o sexo feminino, podiam existir hábitos conformes a seu estado perante a Igreja e a sociedade à data do falecimento.

É igualmente importante relembrar que $12 \%$ dos testadores analisados solicitaram dois hábitos para serem amortalhados, associando geralmente o hábito de São Francisco aos de Santa Teresa e Nossa Senhora do Carmo, ou ao "hábito de viúva". Que motivos levariam a esse procedimento? Pensamos que, ao utilizar dois hábitos, o defunto esperaria duplicar as garantias de salvação e as graças espirituais concedidas à sua alma. A utilização de dois hábitos como mortalha supunha uma maior capacidade financeira por parte do indivíduo. ${ }^{14}$ Ora, se, segundo o preceito cristão, era mais difícil aos ricos obter a salvação, estes lançariam mão de todos os expedientes para atingi-la, entre os quais o amortalhamento com dois hábitos. ${ }^{15}$ No entanto, não podemos excluir a hipótese de alguns testadores pretenderem conferir um maior grau de aparato visual a seu corpo durante o período de velório e do cerimonial fúnebre, seguindo certa sensibilidade barroca. Por outro lado, é igualmente possível que certos indivíduos fossem especialmente devotos desses santos e, desse modo, lhes parecesse pertinente que seus restos mortais fossem amortalhados com os dois hábitos.

Para além desses aspectos, é importante referir ainda ter-se mantido em níveis bastante reduzidos a percentagem de testadores que deixaram a escolha

\footnotetext{
${ }^{10}$ Em Santiago de Compostela, a partir da década de 1730, o hábito de Nossa Senhora do Carmo foi ganhando maior notoriedade, especialmente entre as mulheres, possivelmente em razão da estima e da devoção que Santa Teresa alcança depois de sua canonização. Ver Lopo (2002, p. 319-321). Em Sevilha, ao longo do século XVIII, é igualmente constatável a emergência do hábito carmelita, apesar de se manter o predomínio da mortalha franciscana. Ver Álvarez (1986, p. 119-123). Nas paróquias em torno da cidade de Braga, constata-se igualmente uma preferência pelo hábito de São Francisco, mas os hábitos de Nossa Senhora da Conceição, Santa Teresa e Nossa Senhora do Carmo foram também solicitados por muitas mulheres. Ver Durães (2000, p. 417).

${ }^{11}$ Relativamente à fundação desses conventos, ver Tavares (1998, p. 109 e 124)

${ }^{12} \mathrm{Na}$ verdade, muitos hábitos eram vendidos nos conventos, constituindo-se para eles em fontes de receita. Ver García (2004, p. 447).

${ }_{13}^{13}$ ADB. Testamentos do fundo de Provedoria, cota 454.

${ }_{14}$ Por exemplo, d. Maria Máxima, da família Jacome de Vasconcelos, foi enterrada com o hábito de São Francisco e o de Nossa Senhora dos Remédios. Leia-se a esse respeito Macedo (1996, p. 173-174).

${ }^{15}$ A mortalha carmelita adquirira também indulgências quase tão abrangentes como a franciscana, o que ajuda também a explicar seu sucesso e a utilização simultânea dos dois hábitos por vários defuntos. Sobre essa matéria, ver Fernández (1996, p. 164-165).
} 
da mortalha ao arbítrio dos herdeiros e testamenteiros ao longo do século XVIII. Essa percentagem rondou sempre os 6\%. Os bracarenses atribuíam grande importância às vestes que envolveriam seus restos mortais, deixando determinadas as mortalhas com que desejavam partir para o além. Cremos que não era só a obtenção das graças espirituais que estava presente: a ela se unia uma preocupação com a "imagem" transmitida pelos restos mortais dos defuntos aos vivos, a qual se desejava manter permanentemente dignificada.

Aliás, alguns testadores detiveram-se em detalhes específicos relativos à sua mortalha, patenteando o cuidado extremo que concediam a esse detalhe específico da viagem para o outro mundo. No ano 1729, a testadora Ana Maria Vaz Pereira deixou a escolha da mortalha à decisão das herdeiras, mas referiu que sua última veste tinha obrigatoriamente de incluir uma touca e um manto até os pés. ${ }^{16}$ Outras bracarenses, ao referirem o hábito de Nossa Senhora da Conceição como mortalha, mencionaram que este devia incluir um capelo, um palmito e um lençol para envolver todo o conjunto fúnebre. ${ }^{17}$ Andreia Gomes, viúva do mercador João Fernandes Gentil, da rua das Águas, descreveu em 1751 sua mortalha de viúva como devendo ser composta por um manto de seda e uma touca de escumilha, ao passo que Antônia Maria da Silva solicitou em $1760^{18}$ um hábito de Nossa Senhora do Carmo, com uma touca de Santa Teresa. ${ }^{19}$ Entre os testadores do sexo masculino, um sacerdote pediu para usar, após o falecimento, um escapulário de Nossa Senhora do Carmo por baixo de suas vestes sacerdotais, ${ }^{20}$ enquanto Antônio de Azevedo, do Terreiro do Paço, ${ }^{21}$ optou por utilizar o escapulário e uma capa de Nossa Senhora do Carmo sobre o hábito franciscano. ${ }^{22}$ A preocupação com esses detalhes revela a vontade de alguns testadores de combinarem em sua mortalha diferentes elementos da religiosidade católica.

O número de indivíduos que, em vez de solicitarem um hábito, se conformaram apenas com o pedido de um lençol, ou sudário, para envolver o corpo foi bastante reduzido entre os testadores analisados. ${ }^{23}$ Todavia, é preciso ressalvar um aspecto: geralmente eram os mais pobres que solicitavam apenas essa mortalha, e sabemos que a percentagem de indivíduos pobres que efetuavam testamento era relativamente baixa. Desse modo, pensamos que, entre a população bracarense de fracos recursos, a utilização do lençol como

\footnotetext{
${ }^{16}$ ADB. Testamentos do fundo de Provedoria, cota 82.

${ }^{17}$ ADB. Testamentos do fundo de Provedoria, cotas 408 e 417.

18 ADB. Testamentos do fundo de Provedoria, cotas 293 e 298.

19 Havia até quem se preocupasse em referir o tecido dos hábitos. Encontramos exemplos de mulheres que referiam pretender hábitos de lã, e não de seda. Entre os homens que escolheram o hábito de São Francisco, alguns referiram que este devia ser "inteiro com sua capa”, o que nos faz deduzir que os preços deviam variar conforme os tecidos e as peças que os hábitos podiam incluir (ADB. Testamentos do fundo de Provedoria, cotas 155, 212, 227, 301, 303, 308 e 549; AISB. Livro de testamentos da Sé, 1738-1783, fl. 12).

${ }^{20}$ Os elementos do clero eram sempre sepultados com as vestes sacerdotais. Ver a esse respeito Muñoz (1992, p. 213)

${ }^{21}$ ADB. Testamentos do fundo de Provedoria, cotas 163 e 386

$22 \mathrm{O}$ escapulário carmelita era visto como um instrumento material importante a ser utilizado pelos defuntos que queriam alcançar a salvação. Sobre esse assunto, ver Vovelle (1999, p. 296).

${ }^{23}$ Nas zonas rurais de Braga, no século XVIII, apesar da preferência pelos hábitos religiosos, o uso do lençol como mortalha tinha ainda grande importância. A esse propósito, ver Durães (2000, p. 301)
} 
mortalha terá sido mais prevalente do que à partida esses dados poderão fazer crer. ${ }^{24}$ Por outro lado, a análise testamental revelou que alguns testadores solicitaram ser amortalhados em um hábito franciscano ou de Santa Teresa, "com seu lençol". Seria, afinal, o lençol ainda frequentemente utilizado como mortalha complementar do hábito religioso, motivo pelo qual poucos testadores o referiram de modo específico $?^{25}$ Ou existia, porventura, uma vontade expressa por parte de alguns indivíduos na associação dessas duas peças como mortalha? E, se era esse o caso, com que finalidade? Como forma de reforçar uma posição de humildade na morte? As fontes documentais não nos permitem responder com segurança a essas questões, as quais não quisemos, contudo, deixar de levantar, por nos parecerem pertinentes.

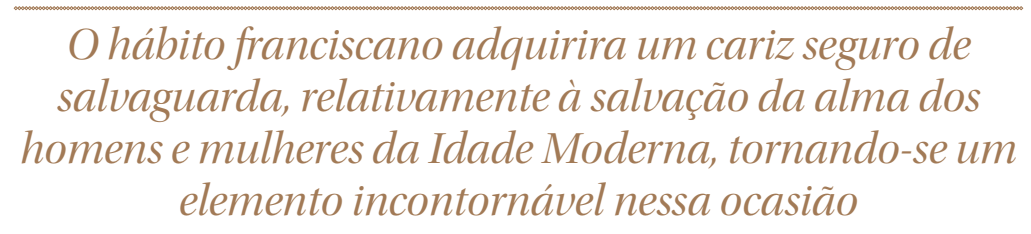

A escolha de hábitos para amortalhar os restos mortais implicava uma despesa para os indivíduos, que, por vezes, definiam os valores monetários a despender para esse fim. Ao revelarem o preço exato de compra dessa veste fúnebre, os testadores davam a entender o tipo de hábito que pretendiam. $\mathrm{Ou}$ seja, os hábitos de uma mesma ordem religiosa podiam ser produzidos de forma mais simples ou complexa, fator que se refletia em seu preço. ${ }^{26}$ Todavia, a inflação dos preços ao longo do século deve ser também levada em conta, pois esse aspecto traduzia-se no fato de que um mesmo tipo de hábito, definido por determinado preço no início do século, acabasse por corresponder a um preço mais elevado no final da centúria.

A maioria dos testadores analisados, $58 \%$, não referiu qualquer preço para as mortalhas que pretendia adquirir, fato que deve ter sido deixado a critério de seus herdeiros ou dos testamenteiros, embora tal não fosse mencionado expressamente. Uma hipótese alternativa a ter em conta pode explicar essa ausência de valores monetários como um sinal indicativo para a compra da mortalha mais comum na época. De fato, alguns dos testadores indicaram que o preço do hábito a adquirir seria o do "costume". Entre os preços que foi possível identificar, verificamos que os hábitos com o custo de 2.400 réis foram os

\footnotetext{
${ }^{24}$ A utilização do sudário ou lençol no século XVIII continuava a ser a mortalha preferida de muitos pobres. Ver sobre esse ponto Gadow (1986, p. 99). Todavia, segundo González Lopo, no século XIX, em Santiago de Compostela, cerca de 90\% dos indivíduos solicitava um hábito para se amortalhar. Ver Lopo (1989, p. 272). ${ }^{25}$ Os estatutos da irmandade de Santa Cruz de Braga de 1773 e 1788 referiam a possibilidade de a instituição apoiar seus confrades pobres para eles adquirirem o hábito e um lençol, dando a entender que as duas peças estavam associadas e a presença do lençol era sempre garantida (Arquivo da Igreja de Santa Cruz (AISC). Fundo da irmandade de Santa Cruz. Livro de estatutos da irmandade de Santa Cruz, 1664, 1702, 1762, 1773, fl. 467v.: Livro de estatutos da irmandade de Santa Cruz, Bom Jesus dos Passos e Santa Ana, 1788, fl. 54v.). ${ }^{26}$ Sobre a existência de hábitos de diferente valor e feitura, ver Lopo (1989, p. 344).
} 
mais procurados até meados do século XVIII. ${ }^{27}$ Correspondem a um total global de $16 \%$ dos testadores analisados. Posteriormente, essa quantia monetária foi suplantada pela correspondente aos hábitos de 4.800 réis entre os homens, pois foram poucas as mulheres que, a partir de 1760, designaram um preço. Essas mortalhas foram designadas por $6 \%$ dos testadores de nossa amostra. Por se tratar de percentagens reduzidas, é difícil afirmar se se constata algum padrão evolutivo. Teriam as mortalhas encarecido substancialmente desde meados da centúria?

Os valores apresentados demonstram também como era difícil aos mais pobres adquirir essa veste fúnebre para amortalhar seus restos mortais, a menos que a obtivessem mediante a caridade alheia. $\mathrm{O}$ recurso a um simples lençol era, desse modo, a solução mais simples e exequível, mas não concedia graças espirituais em benefício da salvação da alma, embora pudesse traduzir a ideia de uma imitação da mortalha de Cristo. ${ }^{28}$ Essa aspiração aos hábitos religiosos como mortalha do corpo dos defuntos levou muitos bracarenses a pedir o auxílio de instituições, como as confrarias, a fim de poder obtê-los. Na verdade, sentindo a morte aproximar-se, muitos homens e mulheres pobres fizeram petições às irmandades, das quais eram confrades, no sentido de lhes ser concedido apoio financeiro para a compra de um hábito religioso. ${ }^{29}$ Em outras ocasiões, os pedidos chegavam às instituições já depois do falecimento do indivíduo, por intermédio de um herdeiro ou de um familiar, o qual solicitava encarecidamente o apoio confraternal para poder amortalhar seu ente querido. ${ }^{30}$

$\mathrm{Na}$ análise das fontes documentais dessas instituições, pudemos constatar que, efetivamente, algumas confrarias previam estatutariamente a concessão de esmolas destinadas à compra de hábitos aos confrades falecidos em estado de pobreza, ${ }^{31}$ como pudemos comprovar em seus livros de despesas. Os estatutos da irmandade de São Pedro dos Clérigos previam a possibilidade de a instituição custear por inteiro a mortalha de seus confrades falecidos em estado de pobreza e desamparo. Na confraria de Santo Amaro da Sé, as regras estatutárias estabeleciam a hipótese de ser dada uma ajuda financeira para seus irmãos pobres adquirirem um hábito conforme sua necessidade.

\footnotetext{
${ }^{27}$ Era também esse o preço prevalente nas freguesias do termo de Braga. Ver Durães (2000, p. 419).

${ }^{28}$ Relativamente à comparação com o sudário de Cristo, ver Lopo (2002, p. 308).

${ }^{29}$ AISB. Fundo da irmandade de São Crispim e São Crispiniano. Livro dos termos da irmandade de São Crispim e São Crispiniano, 1724-1737, fl. 30; Livro de termos da irmandade de São Crispim e São Crispiniano, 1760-1790, fl. 42v:; AISC. Fundo da irmandade do Bom Jesus dos Santos Passos, Livro dos termos de mesa e junta e aceitação de irmãos da irmandade dos Santos Passos, 1686-1740, fls. 397v.398; Arquivo da Igreja de São Vicente (AISVTE). Fundo da irmandade de Santo Homem Bom. Livro dos termos de mesa da irmandade de Santo Homem Bom, 1742- 1765, fl. 204; Fundo da irmandade de São Vicente. Livro de termos de mesa da irmandade de São Vicente, 1700-1720, fls. 91v, 93.

${ }^{30}$ AISB. Fundo da irmandade de São Crispim e São Crispiniano. Livro de termos da irmandade de São Crispim e São Crispiniano, 1760-1790, fls. 183, 277-278; AISC. Fundo da irmandade do Bom Jesus dos Santos Passos. Livro dos termos de mesa e junta e aceitação de irmãos da irmandade dos Santos Passos, 1686-1740, fl. 516; AISVTE. Fundo da irmandade de Santo Homem Bom. Livro dos termos de mesa da irmandade de Santo Homem Bom, 1690-1742, fls. 174v.-175; Fundo da irmandade de São Vicente. Livro dos termos de mesa da irmandade de São Vicente, 1720-1736, fl. 356.

${ }^{31}$ Já na Idade Média, as confrarias custeavam os enterros e a compra de mortalhas para seus confrades pobres. Eram importantes focos de solidariedade na vivência da morte. Ver Abreu (2004, p. 49), Beirante (1990, p. 29) e Jamard (1972, p. 478).
} 
Os dados contabilísticos analisados parecem indicar que esse apoio foi concedido esporadicamente. ${ }^{32}$

Os estatutos da confraria de São Tiago da Cividade eram omissos nessa temática, mas sabemos que, pelo menos em uma ocasião, essa instituição concedeu 480 réis de ajuda a uma irmã para a compra de um hábito. À semelhança do que sucedia na confraria de Santo Amaro, aparentemente esse era um apoio que a confraria de São Tiago concedia muito raramente. ${ }^{33}$ Do mesmo modo, a confraria do Santo Nome de Deus e São Gonçalo, em meados do século XVIII, parece ter concedido um número reduzido de esmolas a alguns confrades para estes poderem se amortalhar com as referidas vestes. ${ }^{34}$ Por seu turno, a irmandade de Nossa Senhora do Ó do Hospital determinava estatutariamente, em 1701, a concessão, por intermédio do tesoureiro, de um hábito envolvente para o corpo dos confrades impossibilitados de o comprarem em razão de seus parcos recursos. Na prática, essa instituição optou pela entrega de ajudas monetárias aos irmãos pobres para lhes ser facultada a referida veste. Os dados dessa irmandade referem um número reduzido de esmolas dadas para esse fim nas décadas de 1730 e 1740, variando seu valor entre 480, 800 e 1.200 réis, a exemplo do sucedido na confraria do Santo Nome de Deus e São Gonçalo. ${ }^{35}$

A confraria de São Crispim e São Crispiniano (dos sapateiros bracarenses), bem como a de Santo Homem Bom (dos alfaiates), forneceu um número maior de esmolas destinadas a esse apoio. Os estatutos de São Crispim, em 1731, definiram uma ajuda de 2.400 réis para a compra de uma túnica de São Francisco aos confrades pobres que tivessem servido nos cargos da mesa da instituição. Esse apoio era somente atribuído se os referidos confrades não tivessem outras instituições confraternais que os ajudassem. Se assim sucedesse, eram apenas concedidos 1.200 réis, valor igualmente atribuído aos restantes confrades pobres que pedissem o apoio da irmandade, para poderem se amortalhar..$^{36}$ Portanto, a irmandade de São Crispim esperava o contributo das outras congêneres nesse apoio específico, privilegiando também aqueles que, no passado, tinham contribuído com seu trabalho e disponibilidade para a gestão da instituição. Os estatutos definiam como obrigatória a compra de um hábito franciscano no valor de 2.400 réis, caso contrário a ajuda não era concedida. Pela análise das fontes dessa instituição, verificamos a atribuição de algumas esmolas destinadas à compra de hábitos para seus confrades entre as décadas de 1730 e 1790, variando essas ajudas entre 600, 800, 960, 1.200,

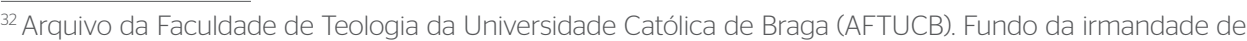
São Pedro dos Clérigos. Livro de estatutos da irmandade de São Pedro dos Clérigos, 1739, p. 64; AISB. Fundo da confraria de Santo Amaro. Livro de estatutos da confraria de Santo Amaro sita na Sé, 1742, fl. 21v.

33 A esmola da irmandade de São Tiago da Cividade foi concedida em 1750 (AISC. Fundo da irmandade de São Tiago da Cividade. Livro dos contratos de dinheiro a juro e seus recibos, 1706-1796, e de receitas e despesas da confraria de São Tiago da Cividade, 1628-1796, fls. 599-600).

${ }^{34} \mathrm{O}$ valor dos apoios financeiros atribuídos variou entre 480, 800 e 1.200 réis (AISC. Fundo da irmandade do Menino Deus e São Gonçalo. Livro dos recibos e despesas da irmandade do Menino Deus e São Gonçalo, 1616-1776, fls. 229-230v., 272-276v., 289-292v., 402v-406, 440-445, 463-465).

${ }^{35}$ AISB. Fundo da irmandade de Nossa Senhora do Ó do Hospital de São Marcos. Livro de termos de mesa da irmandade de Nossa Senhora do O, 1726-1753, fls. 94, 96v., 138v.-139, 190v., 205, 215).

${ }^{36} \mathrm{Em}$ Lisboa, a confraria de São Jorge atribuía um apoio de 1.200 réis aos confrades agonizantes pobres. Ver Santos (2005, p. 189).
} 
1.600 e 2.400 réis. ${ }^{37}$ Desse modo, essa instituição forneceu, por vezes, apoios de menor valor se comparados com aqueles a que se comprometera estatutariamente, possivelmente em razão de situações de maior dificuldade financeira, ou talvez por considerar que o estado econômico-social dos solicitadores não justificava uma despesa de 1.200 réis. Por outro lado, é provável que, relativamente a alguns casos, os confrades pudessem ter contado com a ajuda de várias irmandades, determinando um auxílio menor por parte da irmandade de São Crispim.

Por seu turno, a irmandade de Santo Homem Bom previa, nos estatutos de 1688 e 1725, conceder um hábito a seus irmãos pobres, mas somente na condição de estes serem levados à sepultura em seu esquife. Recordemos que o esquife, também designado por tumba, consistia em uma espécie de "padiola" na qual os defuntos, à vista de todos, eram transportados à sepultura. Diversas instituições, como as irmandades, procuraram munir-se desses objetos. A atribuição desse auxílio ficava, pois, dependente de a instituição poder desfrutar do prestígio e poder simbólico, correspondente ao fato de ser ela a transportar os restos mortais de seus irmãos. Os estatutos de 1773 determinaram especificamente a concessão de 1.200 réis de esmola aos confrades pobres para ajudá-los na compra de um hábito se eles não fossem membros de outra confraria. Neste último caso, a ajuda prestada seria apenas de 600 réis. A irmandade não afastava também a hipótese de, no futuro, vir a dar esmolas a elementos estranhos à confraria, se sua capacidade financeira o permitisse. ${ }^{38}$

Ao confrontarmos os dados apresentados pelas fontes dessa irmandade, constatamos que os apoios atribuídos foram no valor de 480, 940, 720, 800, 1.200 réis e de um "quarto de ouro". Relativamente a alguns casos, foram apenas atribuídos 480 réis em razão de o peticionário já ter a ajuda de outras confrarias. Desse modo, as irmandades analisavam a situação socioeconômica de cada irmão, bem como os auxílios que ele podia obter de outras instituições das quais era membro, de modo a racionalizar seus gastos nessas ajudas. ${ }^{39}$

\footnotetext{
${ }^{37}$ Entre os valores referidos, as esmolas de 800 e 1.200 réis foram as mais atribuídas (AISB. Fundo da irmandade de São Crispim e São Crispiniano. Livro de estatutos da irmandade de São Crispim e São Crispiniano, 1731, fls. 19 e 21; Livro de termos de mesa da irmandade de São Crispim e São Crispiniano, 17241737, fl. 30; Livro de termos de mesa da irmandade de São Crispim e São Crispiniano, 1760-1790, fls. 42v., 245, 265, 277-278; Livro da despesa da irmandade de São Crispim e São Crispiniano, 1711-1810, fls. 99-100, 120v.124, 140v.-143, 206-207v., 225v-226, 257-257v.).

${ }^{38}$ A irmandade do Menino Deus de Maximinos concedia acompanhamento e mortalha aos não confrades falecidos em estado de pobreza. Ver Vieira (1994, p. 38-39). Por seu turno, a Misericórdia de Ponte da Barca atribuía ajudas nas mesmas condições. Ver também Pereira (2005, p. 144). E em El Toboso, Espanha, os membros da confraria local de São Sebastião contribuíam para a compra de mortalhas dos pobres miseráveis que faleciam sem quaisquer bens. Ver Sevila (2006, p. 728).

39 Entre os valores referenciados, as esmolas de 480, 800 e 1.200 réis foram as mais recorrentes (AISVTE. Fundo da irmandade de Santo Homem Bom. Livro de estatutos da irmandade de Santo Homem Bom, 1688, fl. 17; Livro de estatutos reformados da irmandade de Santo Homem Bom 1725, fls. 26, 28v.; Estatutos da irmandade de Santo Homem Bom, 1773, fl. 24v.; Livro de despesa dos tesoureiros da irmandade de Santo Homem Bom, 1757-1783, fls. 18-20, 37-37v.; Livro de missas dos irmãos defuntos da irmandade de Santo Homem Bom, 1744-1783, fls. 53v.-58, 59; Livro dos termos de mesa da irmandade de Santo Homem Bom, 1690-1742, fls. 64v. 174v.175, 188, 203, 221; Livro de termos de mesa da irmandade de Santo Homem Bom, 17421765, fls. 70v., 87v., 99, 204, 249v.).
} 
As irmandades do Bom Jesus dos Santos Passos, de São Vicente e de Santa Cruz, refletindo sua pujança financeira, detinham um papel de destaque entre as confrarias concessoras do maior número de esmolas a seus confrades para eles se amortalharem. No início do século XVIII, a irmandade do Bom Jesus dos Santos Passos tinha em vigor com os frades agostinhos do convento do Pópulo de Braga um contrato que os obrigava ao fornecimento de hábitos de sua ordem para amortalhar os irmãos dessa confraria, a qual pagava 2.000 réis por um hábito que incluía uma correia e capelo. Aos frades agostinhos competia ainda vestir cada confrade defunto, bem como colocá-lo na tumba e descê-lo posteriormente à sepultura. ${ }^{40}$

Todavia, em 1706, em razão da existência de discórdias entre as partes, foi feito um novo contrato, dispensando os frades dessas obrigações. ${ }^{41} \mathrm{~A}$ irmandade começou a proceder como outras congêneres, dando apoio financeiro aos confrades pobres que pedissem ajuda para sua mortalha. Inicialmente, esse apoio era feito conforme o confrade fosse, ou não, apenas membro da irmandade dos Santos Passos. Se fosse somente irmão da confraria, esta comprometia-se a ajudá-lo com esmolas de maior valor, as quais podiam até custear por completo a compra do hábito. Mas, se assim não sucedesse, as outras irmandades de que fosse membro tinham de contribuir de forma equitativa. Essa determinação coloca-nos uma dúvida. Se algumas confrarias não providenciavam esse auxílio aos confrades pobres, o que sucederia se o irmão da confraria dos Santos Passos fosse igualmente membro de uma instituição que não previa uma ajuda semelhante na compra de sua mortalha? A irmandade dos Santos Passos pagaria apenas aquilo que considerava ser de sua competência, agindo como se as outras confrarias também contribuíssem? Ou atenderia às circunstâncias, concedendo apoio ao confrade, como se fosse apenas seu membro? As fontes compulsadas não puderam nos esclarecer sobre esse aspecto.

Nos estatutos de 1740, a irmandade dos Santos Passos estabeleceu a ajuda a conceder, no valor de 1.600 réis, por cada confrade pobre, cifra que baixava para somente 600 réis se porventura o irmão fosse membro de outras confrarias. Ao estudarmos suas fontes, verificamos a dádiva de esmolas para mortalhas aos confrades pobres de modo regular ao longo do século XVIII. Os valores concedidos eram bastante variados. No início da centúria, encontramos esmolas mais baixas, entre 150, 175 ou 240 réis, mas também ajudas de valor mais elevado, variando entre 800, 840, 960, 1.200 e 2.400 réis. As esmolas eram concedidas sem ser avançada uma explicação para seu valor, embora em um caso fosse explicitado que este se devia ao fato de o confrade ser membro de outras irmandades, as quais também contribuíram para o custo da mortalha. Pensamos ser esse o critério principal seguido, preceituado, aliás, nos estatutos. A partir de 1740, como mencionamos, o critério definido estatutariamente

${ }^{40}$ Do mesmo modo, também a confraria de Nossa Senhora da Encarnação da Ameixoeira tomava a seu cargo o cuidado com os cadáveres de seus membros, vestindo-os para a sepultura. A propósito dessa ação caritativa, ver Gomes (2007, p. 94-95).

${ }^{41}$ AISC. Fundo da irmandade do Bom Jesus dos Santos Passos. Reforma do contrato entre os religiosos do Pópulo e a irmandade dos Santos Passos, 1706, fls. 1-19. 
devia ser uniforme: eram atribuídos 1.600 réis de ajuda aos confrades que eram unicamente membros da irmandade do Bom Jesus dos Santos Passos e 600 réis aos que também o fossem de outras instituições congêneres. Contudo, a análise das fontes mostra-nos que nem sempre as mesas assim procederam. $\mathrm{Na}$ verdade, encontramos esmolas destinadas às mortalhas dos confrades pobres no valor de 480, 700, 800 e 1.200 réis, para além dos valores preceituados nos estatutos. ${ }^{42}$ Talvez a irmandade fosse, por vezes, flexível na prestação dessas ajudas, conforme o estado de pobreza do confrade, bem como do número de confrarias contribuintes nesse auxílio.

\section{Algumas confrarias previam estatutariamente a concessão de esmolas destinadas à compra de hábitos aos confrades falecidos em estado de pobreza}

Os dois estatutos setecentistas da irmandade de São Vicente determinavam a compra por parte da instituição de um hábito para amortalhar seus confrades falecidos em estado de grande pobreza, se não fossem membros de outra "irmandade mais velha", ou seja, de uma confraria mais antiga. Portanto, a instituição tomava estatutariamente o encargo de adquirir a mortalha, tarefa que, por vezes, efetuou por intermédio de seu servo, ${ }^{43}$ embora não saibamos se, em várias ocasiões, ela não terá se limitado apenas a conceder a esmola solicitada. Os estatutos de 1768 explicitavam a concessão aos irmãos pobres de uma esmola de 1.200 réis destinada à compra do hábito para se amortalharem, sob condição de ser a irmandade de São Vicente a escolhida para transportá-los no esquife até a sepultura, à semelhança do verificado na irmandade de Santo Homem Bom. Ou seja, a confraria custeava a mortalha mediante a condição do confrade lhe conceder um lugar de destaque no acompanhamento fúnebre. Era a concessão de esmola a funcionar sob o duplo aspecto da prestação de caridade e de reforço do prestígio social da irmandade. ${ }^{44}$

Todavia, como procedeu efetivamente a confraria nessa distribuição de esmolas para as mortalhas? Apesar de as informações provenientes das fontes compulsadas não serem completas, os dados recolhidos mostram que,

\footnotetext{
${ }^{42}$ AISC. Fundo da irmandade do Bom Jesus dos Santos Passos. Livro de estatutos da irmandade do Bom Jesus dos Santos Passos, 1707, fl. 36v:; Livro de estatutos da irmandade do Bom Jesus dos Santos Passos, 1740, fl. 129; Livro das certidões das missas dos irmãos defuntos da irmandade dos Passos e Santa Ana, 1752-1778, fls. 536v.-571; Livro das despesas da irmandade do Bom Jesus dos Santos Passos, 1628-1772, fls. 302-305, 323v. 326, 415v., 448-453, 524-527v., 567v.571, 692-699, 717v., 719-724v.; Livro dos termos de mesa e juntas e aceitação de irmãos da irmandade dos Santos Passos, 1686-1740, fls. 165, 194v., 226, 372, 397v-398, 413, 418, 504v., 513-514, 516, 529, 545v:; Livro de termos de mesa da irmandade do Bom Jesus dos Santos Passos, 1740-1772, fls. 79, 168, 199, 207v., 399v., 400, 462, 463, 511, 520, 594, 682

${ }^{43}$ Certas irmandades tinham um indivíduo designado por "servo" a seu serviço. O servo era uma espécie de "sacristão" da irmandade, ocupando-se da limpeza da igreja, das tarefas referentes à manutenção do culto, do enterro dos defuntos e ainda de outras funções.

${ }^{44}$ Para além do apoio à compra da mortalha, algumas confrarias medievais de Leão e Castela proporcionavam explicitamente apoio alimentar a seus irmãos pobres enfermos. Para esse auxílio, ver Arce (2009, p. 89-90).
} 
até meados do século XVIII, as esmolas concedidas variaram sobretudo entre 480, 600, 720, 800 e 1.200 réis, com maior relevância para o último valor. Posteriormente, já sob a vigência dos estatutos de 1768, o montante das esmolas subiu, sendo sobretudo atribuídas as de 800, 1.200 e 1.600 réis. Em termos absolutos, as ajudas financeiras concedidas em maior número foram as de 1.200 e 800 réis. Como podemos verificar, apesar de a norma estatutária prever o pagamento de 1.200 réis, a partir de 1768 a instituição, a exemplo das congêneres, flexibilizava os montantes a conceder, tendo possivelmente em conta as verdadeiras necessidades dos peticionários, bem como a situação financeira da irmandade. Outro aspecto a sublinhar é o de que, nas primeiras duas décadas do século XVIII, termos referência a poucas esmolas atribuídas. Esse fato poderá ter sido motivado por lacunas em nível documental, mas não podemos afastar a hipótese de o número de esmolas fornecidas no início da centúria ter sido menor. Parece igualmente denotar-se certo abrandamento na atribuição de ajudas nas últimas duas décadas setecentistas, possivelmente em razão da difícil situação financeira da confraria.

Como os apoios financeiros foram sobretudo no valor de 1.200 e 800 réis, eles serviam para adquirir as mortalhas mais baratas, destinadas aos mais necessitados, ou, em alternativa, serviam como complemento para os parcos recursos desses confrades pobres. Ainda assim, constatamos que, no final do século, a irmandade deu algumas esmolas mais avultadas, no valor de 2.200, 2.400 e 3.000 réis, a um número restrito de confrades, talvez por terem desempenhado cargos na mesa, ou por especial favor dos gerentes de então. Não podemos igualmente pôr de lado a hipótese de se tratar de irmãos em situação de pobreza envergonhada, ${ }^{45}$ apenas do conhecimento dos responsáveis da irmandade, a quem pediam discretamente esse apoio. ${ }^{46}$

Por seu turno, a irmandade de Santa Cruz concedeu igualmente vários apoios financeiros no sentido de ajudar no amortalhamento dos confrades pobres. As regulamentações estatutárias de 1702 e 1762 determinavam a coparticipação financeira da instituição na compra de hábitos para os confrades, podendo, em alternativa, tomar para si a tarefa de adquiri-los por intermédio do tesoureiro, sob autorização escrita do juiz ou do secretário. Os estatutos de 1773 adotaram um critério mais restritivo, a exemplo do que constatamos igualmente em outras confrarias. A irmandade facultava um hábito, a que acrescentava um

\footnotetext{
${ }^{45}$ De fato, os pobres envergonhados escondiam sua situação de carência financeira e econômica, comunicando-a a um pequeno grupo de indivíduos que podiam ajudá-los. A esse propósito, leia-se Araújo (2002, p. 116-117).

${ }^{46}$ AISVTE. Fundo da irmandade de São Vicente. Livro de termos de mesa da irmandade de São Vicente, 1701-1720, fls. 91v., 93; Livro de termos de mesa da irmandade de São Vicente, 1720-1736, fls. 54V., 142v., 146v., 148v., 155v., 174v.199, 224, 227v., 241v., 302v., 327-328v., 356; Livro de termos de mesa da irmandade de São Vicente, 1736-1748, fls. 19v-20, 31, 32v., 92v., 115v., 121v., 155, 161, 169, 181v., 247, 262v.; Livro de termos de mesa da irmandade de São Vicente, 1748-1765, fls. 55v., 213, 242, 360, 425v:; Livro de termos de mesa da irmandade de São Vicente, 1765-1772, fls. 4, 5v., 11v., 15, 119v., 123v., 140, 158v., 166, 176v., 181v., 205, 213v., 222; Livro de termos de mesa da irmandade de São Vicente, 1772-1781, fls. 103, 137v., 206, 247v.; Livro de termos de mesa da irmandade de São Vicente, 1781-1790, fls. 73v., 83v., 122, 124v., 284v.; Livro de termos de mesa da irmandade de São Vicente, 1790-1796, fls. 49, 87; Livro de termos de mesa da irmandade de São Vicente, 1796-1803, fls. 2, 7v., 62, 73, 75, 84v.; Livro da despesa da irmandade de São Vicente, 1732-1759, fls. 32v-44, 72v-77, 132-136, 154-157v., 175v.-183v., 206v.-214; Livro da despesa da irmandade de São Vicente, 1768-1811, fls. 68v.-74, 136v.138.
} 
lençol, para amortalhar os irmãos pobres, mas exigia aos confrades, para além de comprovarem sua situação de pobreza por ocasião de sua morte, escolherem a instituição para transportá-los em sua tumba. Desse modo, a irmandade de Santa Cruz seguia o exemplo de outras congêneres ao condicionar sua ajuda ao fato de os peticionários designarem a irmandade auxiliadora para transportá-los à sepultura. Assim, como já referimos, a caridade exercida tinha como contrapartida o prestígio e a projeção social da confraria perante a comunidade e não era efetuada de forma completamente desinteressada. ${ }^{47}$

Os estatutos de 1788 mantiveram as ajudas para a compra de hábitos e lençóis para os confrades pobres, uma tarefa que devia recair nos mordomos depois de o provedor ser avisado. ${ }^{48}$ Contudo, o critério de prestação desse apoio tornou-se ainda mais apertado. O confrade tinha de escolher a irmandade de Santa Cruz como transportadora de seus restos mortais à sepultura e de requerer a contribuição financeira das confrarias a que eventualmente pertencesse para a compra da mortalha. ${ }^{49}$ Novamente nos interrogamos sobre qual seria a atuação da irmandade, se porventura as outras confrarias não apoiassem seus confrades pobres. A irmandade de Santa Cruz manteria sua decisão prevista nos estatutos, ou teria maior atenção à especificidade de cada caso? Por outro lado, podiam as outras confrarias esquivarem-se dessa obrigação?

Apesar de os dados levantados nas fontes não serem completos, tentamos delinear a tendência seguida por essa instituição na ajuda ao amortalhamento de seus confrades defuntos. As fontes documentais estudadas relativas à irmandade de Santa Cruz demonstram que as quantias despendidas com as mortalhas foram, sobretudo, de 1.200 e 2.400 réis. De forma muito semelhante ao que se verificou na irmandade de São Vicente, as duas primeiras décadas foram marcadas por uma ausência de referências à disponibilização de dinheiro para a compra de hábitos. Cremos que, apesar da existência de algumas lacunas documentais, essa não terá sido uma ajuda que a confraria concedesse em larga escala. A partir de 1720 até 1760, a quantia de 2.400 réis foi a mais atribuída, indicando que, provavelmente, a confraria ajudaria na compra de mortalhas com esse custo. Pelo contrário, a partir de 1780 assistimos a um claro predomínio do auxílio no valor de 1.200 réis, apesar de aparecerem alguns exemplos esporádicos de esmolas acima desse montante. Relembramos que, na tabela dos preços das mortalhas indicados pelos testadores, os valores de 1.200 e 2.400 réis foram os mais praticados até meados do século XVIII, substituídos posteriormente pelo de 4.800 réis. A alteração verificada parece refletir a estratégia seguida pela instituição nas últimas décadas da centúria: conceder ajudas apenas aos que escolhiam a tumba da confraria para o funeral, bem como a determinação de partilhar os custos das mortalhas com outras

\footnotetext{
${ }^{47}$ AISC. Fundo da irmandade de Santa Cruz. Livro de estatutos da irmandade de Santa Cruz, 1664, 1702, 1762, 1773, fls. 273, 379, 467v., 482

48 O provedor, ou juiz, era a autoridade máxima das confrarias, presidindo à mesa administrativa. Os mordomos faziam igualmente parte desta última.

${ }^{49}$ AISC. Fundo da irmandade de Santa Cruz. Livro de estatutos da irmandade de Santa Cruz, Bom Jesus dos Santos Passos e Santa Ana, 1788, fl. 54v.
} 
instituições congêneres às quais o peticionário pertencesse. Por outro lado, é possível ter existido por parte da confraria uma restrição dos montantes financeiros atribuídos, ou uma escolha deliberada pela compra dos hábitos mais baratos, em uma altura de maior aperto financeiro. ${ }^{50}$

Ainda assim, verificamos novamente a concessão a um número reduzido de confrades de ajudas mais generosas, entre 2.600 e 3.990 réis. ${ }^{51}$ É possível que os motivos para esse fato fossem os mencionados quando da análise do quadro evolutivo relativo à irmandade de São Vicente. Contudo, não podemos pôr de lado a hipótese de, em ambos os casos, estarmos perante irmãos em situações de pobreza envergonhada. Na verdade, provavelmente houve confrades que procuravam transmitir certa posição social, mas que, à hora da morte, se encontravam em uma situação efetiva de pobreza, não condizente com seu estatuto. Essa situação seria somente do conhecimento da mesa das confrarias a que pertenciam. Consequentemente, esses confrades solicitavam discretamente a ajuda da irmandade, tendo como objetivo serem amortalhados com um hábito mais caro, de acordo com seu estatuto social. Essa é uma hipótese que, no caso da irmandade de Santa Cruz, ganha mais força se recordarmos que essa era uma instituição social na qual ingressavam as elites e os grupos mais favorecidos da cidade.

Da análise das fontes documentais confraternais, podemos concluir que as esmolas concedidas por algumas irmandades foram um apoio importante aos confrades pobres como forma de poderem amortalhar de forma "digna" seu corpo. Os valores das esmolas atribuídas parecem fazer supor uma indicação das confrarias a seus membros mais necessitados para que eles adquirissem os hábitos mais baratos. Em alternativa, os apoios concedidos podem ser percecionados apenas como uma ajuda parcial aos irmãos com poucos recursos para que estes adquirissem as mortalhas a seu critério. Apesar de as confrarias, por vezes, estabelecerem estatutariamente os valores das esmolas a atribuir, na realidade agiam com alguma flexibilidade, despachando ajudas conforme julgassem ser mais pertinente. Os valores enunciados nas fontes documentais indicam também que só as confrarias com robustez financeira podiam conceder essas ajudas regularmente em razão do custo que implicavam. Essa poderá ser a razão pela qual a maioria das instituições confraternais analisadas não previa uma tal modalidade de assistência nos estatutos para além de não termos encontrado sobre ela qualquer menção em seus fundos documentais. Por outro lado, esse apoio caritativo aos confrades tinha por vezes como contrapartida, a exigência de nomeação da organização confraternal a

${ }^{50}$ AISC. Fundo da irmandade de Santa Cruz. Livro de termos de mesa e juntas das irmandade de Santa Cruz, 1701-1734, fl. 636v:; Livro de termos de mesa e juntas da irmandade de Santa Cruz, 1735-1757, fls. 90, 105V., 256, 357; Livro dos termos de mesa e juntas da irmandade de Santa Cruz, 1757-1772, fls. 233, 274, 281v., 326v., 453v.454; Livro de termos de mesa e juntas da irmandade de Santa Cruz, 1772-1790, fls. 78v., 232v.; Livro de termos de mesa e juntas da irmandade de Santa Cruz, 1790-1819, fl. 212; Livro segundo das despesas da irmandade de Santa Cruz, 1720-1802, fls. 78, 89v-93, 99, 104, 130, 134v., 149-154, 188, 195v., 202, 305-309, 318, 326, 341v., 368375v., 388, 394, 396, 426, 468, 487, 493v., 501-505.

${ }^{51}$ A confraria do Corpo Santo do Funchal destinava 3 mil réis, no século XVIII, para ajudar seus confrades marinheiros e pescadores na compra de uma mortalha. Ver, a esse respeito, Veríssimo (1992, p. 118). 
que pertenciam para levá-los à sepultura, em sua tumba. Com essa obrigação, as confrarias pretendiam garantir um lugar de destaque no enterro de seus membros, reforçando seu poder, influência e prestígio sociais.

Para além desse aspecto, a utilização do hábito religioso proporcionava, como vimos, a concessão de indulgências à alma do defunto, ou seja, o perdão dos pecados e garantias mais seguras do alcance da salvação. Por isso, os testadores bracarenses atribuíam grande importância à escolha da mortalha, investindo seus meios na compra de hábitos, como o franciscano ou o carmelita, ou procurando ajuda externa para esse fim.

\section{Referências bibliográficas}

ABREU, Laurinda. Confrarias do Espírito Santo e misericórdias: um percurso histórico moldado pela intervenção régia. In: Em nome do Espírito Santo: história de um culto. Lisboa: Torre do Tombo, 2004.

ÁLVAREZ, José António Rivas. Miedo y piedad: testamentos sevillanos del siglo XVIII. Sevilha: Diputación Provincial de Sevilla, 1986.

ARAÚJO, Ana Cristina. Morte. In: AZEVEDO, Carlos Moreira (Org.). Dicionário de história religiosa de Portugal. Lisboa: Círculo de Leitores, 2000.

ARAÚJO, Maria Marta Lobo de. Aos pés de Vossa Alteza Sereníssima: as pobres do arcebispo bracarense d. José de Bragança. Cadernos do Noroeste, Braga, v. 17, n. 1-2, p. 116-117, 2002.

ARCE, José Damián González. Gremios y confradías en los reinos medievales de León y Castilla siglos XII-XV. Palencia: Región, 2009.

BEIRANTE, Maria Ângela Godinho. Confrarias medievais portuguesas. Lisboa, 1990. Publicação da autora.

DURÃES, Margarida. Herança e sucessão: leis, práticas e costumes no Termo de Braga (séculos XVIII-XIX): Braga: Instituto de Ciências Sociais da Universidade do Minho, 2000. t. II.

. Porque a morte é certa e a hora incerta... Alguns aspectos dos preparativos da morte e da salvação eterna entre os camponeses bracarenses (séculos XVIII-XIX). Cadernos do Noroeste, Série Sociologia, Braga, v. 13, n. 2, p. 301, 2000.

FERNÁNDEZ, Maximo Garcia. Los castellanos y la muerte: religiosidad y comportamentos colectivos en el Antíguo Régimen. Valladolid: Junta de Castilla y Léon, 1996.

GADOW, Marion Reder. Morir en Malaga: testamentos malagueños del siglo XVIII. Málaga: Universidad de Málaga, 1986.

GARCÍA, Alfredo Martín. Religión y sociedad en Ferrolterra durante el Antiguo Régimen: la V. O. T. seglar franciscana. Estudios Mindonienses, Salamanca, n. 20, p. 445-446, 2004.

GOMES, Maria Teresa de Moura Benedito. A confraria de Nossa Senhora da Encarnação da Ameixoeira nos séculos XVI eXVII e os poderes locais. Lisboa: Faculdade de Letras da Universidade de Lisboa, 2007.

ILLÁN, Anastasio Aléan. Actitudes colectivas ante la muerte en Múrcia durante el siglo XVIII. Cadernos de Historia Moderna, Madri, n. 9, p. 100, 1998.

JAMARD, Jean-Luc. Confréries religieuses et dichotomie sociale. Mélanges de la Casa de Velázquez, Madri, v. VIII, p. 478, 1972.

LOPO, Domingos González. La mortaja religiosa en Santiago entre los siglos XVI y XIX. Compostellanum, Santiago de Compostela, v. XXXIV, n. 3-4, p. 272, 1989.

. Los comportamientos religiosos en la Galicia del Barroco. Santiago de Compostela: Xunta de Galicia, 2002.

MACEDO, Ana Maria da Costa. Família, sociedade e estratégias de poder, 1750-1830: a família Jácome de Vasconcelos da freguesia de São Tiago da Cividade - Braga. Braga: APPACDM Distrital de Braga, 1996.

MARQUES, João Francisco. Oração e devoções. In: AZEVEDO, Carlos Moreira (Org.). História religiosa de Portugal. Lisboa: Círculo de Leitores, 2000. v. 2. 
MUÑOZ, Miguel Luiz Lopez. Las cofradías de la parroquía de Santa Maria Magdalena de Granada en los siglos XVII-XVIII. Granada: Universidade de Granada, 1992.

PEREIRA, Maria das Dores Sousa. A assistência à alma na Misericórdia de Ponte da Barca (16301800). NW. Noroeste: Revista de História, Braga, n. 1, p. 144, 2005.

RODEÑAS, Manuel José de Lara; CRUZ, David González. Piedad y vanidades en la ciudad de Moguer: un modelo de mentalidade religiosa y ritual funerário en el barroco del 1700. Huelva en Su Historia, Huelva, n. 2, p. 514, 1988.

RODRIGUES, Cláudia. Lugares dos mortos na cidade dos vivos: tradições e transformações fúnebres no Rio de Janeiro. Rio de Janeiro: Secretaria Municipal de Cultura/Departamento Geral de Documentação e Informação Cultural, 1997.

SANTOS, Georgina Silva dos. Ofício e sangue: a irmandade de São Jorge e a Inquisição na Lisboa moderna. Lisboa: Colibri, 2005.

SEVILA, F. Javier Campos y Fernández de. Instituciones privadas de caridade en las "relaciones topográficas". In: (Org.). La Iglesia española y las instituciones de caridad. Madri: Escurialenses, 2006.

TAVARES, Pedro Vilas Boas. Instituição e vicissitudes de um beatério quinhentista: as beatas do Campo da Vinha (Braga). Notas e rotas de investigação. Via Spiritus: Revista de História da Espiritualidade e do Sentimento Religioso, Porto, n. 5, p. 107-132, 1998.

VERÍSSIMO, Nelson. A confraria do Corpo Santo no século XVIII. Islenha, Funchal, n. 10, p. 118, 1992.

VIEIRA, Maria José de Azevedo. A confraria do Menino Deus e a paróquia de Maximinos (17001850): população, sociedade e assistência. Braga: Instituto de Ciências Sociais da Universidade do Minho, 1994.

VOVELLE, Michel. Aspects populaires de la dévotion au Purgatoire à l'Âge Moderne dans l'Occident chrétien: le témoignage des représentations figurées. In: COLÓQUIO INTERNACIONAL PIEDADE POPULAR: SOCIABILIDADES, REPRESENTAÇÕES E ESPIRITUALIDADES. Anais... Lisboa: Terramar, 1999. 